\title{
"I'm not that important": Barriers and bolsters to student agency during conversations about the intersections of physics and ethics
}

\author{
Brianne Gutmann, Egla Ochoa-Madrid, and Alice Olmstead \\ Department of Physics, Texas State University, 749 N. Comanche Street, San Marcos, TX, USA, 78666
}

Physics has greatly impacted society, both in solving problems and perpetuating harm. Yet we rarely train physics students to grapple with their responsibilities to society by facilitating conversations about ethical issues. We developed and collected classroom video of a unit on the development of the atomic bomb. Here, we analyze a set of students' small group interactions to reveal factors that enable and limit their engagement. Enabling factors include: (a) curricular materials that elicit students' opinions, (b) opportunities for students to push each other to engage with the content, and (c) instructor facilitation that further pushes and validates student reasoning. Limiting factors include: (a) students' discomfort around inexperience with ethical reasoning in physics, (b) students' anticipation of their lack of agency in the physics community, and (c) students' projections of their lack of agency in a historical context due to their race and gender. We consider the implications of these factors for instruction.

\footnotetext{
2020 PERC Proceedings edited by Wolf, Bennett, and Frank; Peer-reviewed, doi.org/10.1119/perc.2020.pr.Gutmann Published by the American Association of Physics Teachers under a Creative Commons Attribution 4.0 license. Further distribution must maintain the cover page and attribution to the article's authors.
} 


\section{INTRODUCTION}

Historically and currently, the role of scientists to engage with societal needs and their research's impacts on society have been contested within the scientific community [1-9]. In the scope of internal responsibility, there is general consensus in codes of ethics around professional practices (read: data integrity, plagarism) $[1,3,7,8]$ but scientists disagree about their responsibilities to broader society [1-4, 8, 10]. As early as the 1600s, Francis Bacon cited the humanitarian goal of science as a tool for "the relief of the human condition" [2], while others cite the perception of science's purpose as solely the acquisition of knowledge [9, 11]. Across scientific disciplines, a survey by the AAAS showed that engineers in their sample were least likely to feel a sense of responsibility towards society [1, 2], and one of engineering students across four institutions showed a declining sense of concern for public welfare over their engineering degrees [12].

Scientists' rejection of social responsibility is often enabled by the pervasive idea that social considerations will compromise scientific objectivity [3, 4, 13]. Many believe that science is and should be free from societal pressure in order to create unbiased knowledge, and that it is the responsibility of society (not scientists) to manage its application. Others believe scientists will naturally generate societal benefits through their work. Glerup and Horst argue that this stance relies on the assumption of "science as a fundamentally 'good' institution that has an in-built capacity to know how to serve society best" [3]. Still others posit that "asking scientists to be socially responsible ... would be to give power to a group who are neither trained nor competent to exert it" $[3,13]$. Cech argues that such beliefs are embedded in engineering culture and perpetuate disengagement with social responsibility $[12,14]$.

Despite the glorification of science as being above or removed from society, science and society cannot be separated. Harding explains: "[T]he way in which the ideal of objectivity is talked about on campuses and in public debates is at odds with the actual histories and present practices of the sciences and their philosophies. Sciences and philosophies have never been value-free. They have always been integrated with their particular social and historical contexts" [15]. Glerup and Horst also claim that regardless of how scientists frame the interactions of science and society, there is always a relationship between them [3]. Speaking to responsibility, Douglas argues that scientists cannot escape their moral obligations to society as individuals within a society, noting that scientific work does not preclude those obligations [4].

A culture of disconnect between science and social responsibility can be especially alienating to underrepresented students of color, who tend to place stronger value in careers that enable them to work for social change $[16,17]$. McGee and Bentley, in interviews with Black and Latinx STEM students, noted students' tensions between their commitment to their communities and their expectations of the impact of their career trajectories. These tensions were often unresolved and left students feeling a need to choose between them [16].

We argue that having direct conversations about ethics, science, and society in science classrooms can challenge the narrative of objectivity and encourage the next generation of scientists to engage with societal issues. Some programs train students in the ethics of professional practices. It is equally important to give students practice grappling with ethical issues around science in society [6]. Facilitating these conversations could both help students become more comfortable and competent in discussing scientists' ethical responsibilities, and contribute to normalizing such discussions.

Within engineering education, there is push to incorporate ethics training into curricula $[18,19]$. Although much of the focus is around the ethics of professional practices, some advocate to focus on large-scale ethical issues [6, 7, 20, 21]. At Texas State University, we have developed and have been teaching an ethics unit around physicists' role in the development of the atomic bomb since 2018. The unit structure was adapted from Hess et al's pedagogical model [22]. More information about our selection of this model, key aspects of our curriculum, and students' written interpretations of the ethical framework we used are included in our previous publication [23]. In this paper, we aim to unpack students' in-the-moment interactions and learning. We present a case study of interactions which give insight into the following research questions: What enables and/or limits physics students in grappling with physicists' responsibilities in society in the context of a unit about the ethics of developing the atomic bomb? How do students' positioning of themselves as physicists or not influence their engagement?

\section{METHODS}

\section{A. Classroom Context}

This study took place at Texas State University, a large, diverse Hispanic-Serving Institution in central Texas, in a Physics department which averages around 20 physics majors per year. The students in the study were enrolled in Modern Physics, the first upper-division physics course required for majors and minors at Texas State. The classroom consisted of 23 students (36\% women, $64 \%$ men; $50 \%$ white, $36 \%$ Hispanic/Latinx, $14 \%$ identifying as both Hispanic/Latinx and white), three student instructional assistants ( 2 white men and 1 Hispanic/Latinx man), and one faculty instructor (a white woman). The class was typically taught via structured group work around key concepts (e.g., [24]) and with Learning Assistants (LAs) [25]. The nuclear physics unit was the penultimate unit of the semester, so students already had been working together in small groups for multiple months.

After covering nuclear fission, fusion, and nuclear stability, the students participated in a two-week sub-unit on nuclear ethics surrounding the development of the atomic bomb. A series of worksheets (designed by the 3rd author) scaffolded students' small group conversations. Students began by collectively outlining the key events and stakeholders related to The Manhattan Project and co-developed classroom discus- 
sion norms in anticipation of the sensitive nature of ethical discussions. The instructor referred to Arao and Clemens' recommendations around "brave spaces" to facilitate and guide the norms [26]. Students also read Beauchamp's "Four Principles' Approach to Health Care Ethics" [27], and then were asked to apply the ethical framework to historical letters between various stakeholders during The Manhattan Project. The letters were excerpts from Kelly's The Manhattan Project: The Birth of the Atomic Bomb in the Words of Its Creators, Eyewitnesses, and Historians [28].

\section{B. Analytic Approach}

We video-recorded students' in-class discussions and collected their written work, homework, and exam responses relevant to the nuclear ethics unit. We take a sociocultural approach that posits that student interactions with each other are integral to their learning $[29,30]$, and as such, focus primarily on analyzing classroom video. The first and second authors each independently content logged all 12 hours of classroom video from the semester, which was primarily student discussion with some facilitation. Together, they discussed points of interest and iteratively refined their interpretations, co-creating a collective content log which included instances of students grappling with their own and/or physicists' responsibilities to society [31].

We identified one set of student interactions during a particular class period in which students often brought up these ideas. These interactions serve as a case study for the focus for this paper [32]. The small group consisted of five students (all names are pseudonyms): Grant (a white man), Alexa (a Hispanic/Latinx and white woman), Kevin (a white man), Elize (a white woman), and Jasmine (a Hispanic/Latinx woman). In working through ideas, the group also interacted with an LA, Doug (a white man), and the faculty instructor, Dr. Halsey (a white woman).

Because students' voiced ideas provide valuable evidence about what they are grappling with during class, we focus primarily on the most vocal students: Alexa and Grant. We specifically chose to highlight these episodes because Alexa's engagement aligned well with our research questions, as she often grappled with the role of scientists in ethical discussions and discussed her view of herself as a potential scientist. In addition, her orientation to the discussion shifts noticeably throughout the class period-she initially resists forming and articulating an opinion but ultimately converges on a stance. As such, we set out to unpack how and why that shift occurred as a way of identifying enabling and limiting factors for students' engagement in ethical reasoning.

\section{RESULTS}

All of the following episodes take place on the same day of class, towards the beginning of the nuclear ethics unit. Students have recently been asked to read about Einstein's decision to advocate for the development of the atomic bomb and read his letter to Roosevelt. The prompt on the worksheet reads: "What do you think about the decision Einstein made to advocate for the development of the atomic bomb? Would you have made the same decision? Why or why not?"

Immediately before Episode 1, the student group and Doug (an LA) have been focusing on eliciting Elize's opinions. Elize becomes uncomfortable and asks Alexa for her opinion to shift the focus of the conversation.

\section{Episode 1: I've never been put in this situation}

Alexa: Well I am currently brain-dead, I don't know what I think.

Elize: What!?

Grant: Interesting. So brain-dead you, would you advocate the development of the atomic bomb?

Alexa: I've never been put in this situation so I can neither make a statement...(everyone laughs, Alexa starts laughing also)

Elize: Oh, because I've been in this situation...

Alexa: I don't know, I don't like this. This makes me uncomfortable. 'Cause then it's like, I can see both sides!

Doug (LA) (to Alexa, as other conversations continue): That's the point, it's difficult.

Alexa: What happens if we didn't kill all those people, then somebody really important could have been there who could have like, progressed us even further.

Kevin: We also could have killed the next Hitler.

Alexa: Okay. (shakes her head, laughs)

Doug (LA): Well like, going into this, I ... what perspective did you have? Did you say like "Yeah we should drop the bomb"?

Alexa: I never really had a strong advocacy for it because I never really thought about it.

Doug (LA): ...just like a snap judgement, kinda like...

Alexa: No, I don't think that anybody should ever be harmed.

This clip shows Alexa's initial orientation to taking a stance and the beginnings of her reasoning around the ethics of developing the bomb. She initially declines to give an opinion, but Grant and Elize push her, especially after Elize has just been uncomfortably the center of attention. When Alexa says that she has never been in this situation, the group laughs and begins to chatter with each other while Alexa explains that she's uncomfortable and dislikes taking a side. While the rest of the group is preoccupied with other conversations, Doug responds to Alexa and they begin a side conversation (with Kevin listening). In the one-on-one conversation, Alexa's demeanor becomes more serious and she reflects on why she's not taking a stance: she has never thought about this. Doug presses her to give a gut reaction by voicing a possible stance 
that she could adopt or reject and empathizing with her struggle to do so based on his own experience as a student in this class in a previous semester. This provides an opportunity for her to begin to unpack her own values, stating "I don't think that anybody should ever be harmed."

Around 10 minutes later, the group has moved on to discuss a letter from a panel of scientists who advocate for the immediate use of nuclear weapons. The students are responding to the prompt: "Now, consider the excerpt from the Science Panel's report titled 'No acceptable alternative.' What were the main arguments being made by these physicists?' Specifically, students are discussing the last paragraph of the letter, where the scientists add that they have "no special competence in solving the political, social, and military problems which are presented by the advent of atomic power" [28].

\section{Episode 2: We're incompetent}

Alexa: (laughing) I love the last line of this one, we have no competence in making political decisions, basically. We're incompetent so it's up to you guys.

Dr. Halsey: Yeah, I thought that was funny too.

Alexa: That's the best way ever, just claim no competence for every bad decision.

Grant: (joking) I'm a doctor dammit, not a politician!

Dr. Halsey: Yeah, they're like, "We suggest you build these things but also... we're incompetent!"

Alexa: (simultaneously) ...we're incompetent!

This episode shows Alexa challenging the scientists' abdication of responsibility for their proposed position. The letter gives strong recommendations for action but the scientists also cite themselves as incompetent after doing so. Alexa cites this framing as a convenient way to get out of "every bad decision," a criticism shared by other scholars [4, 5]. Grant and Dr. Halsey validate Alexa's stance by joining her in jokingly criticizing these past scientists.

Soon afterwards, the group begins to talk about their personal stances. Alexa reflects on her preference to not engage in the debate. Grant pushes back, comparing her to the scientists who cited incompetence.

\section{Episode 3: I'm not that important}

Alexa: I prefer to check out into blissful ignorance and watch Netflix and cuddle with my dog...

Grant: You're just like these scientists!

Alexa: ...although, that's probably worse.

Grant: You're the reason the atomic bomb was developed. You're the reason why the atomic bomb 2.0 is going to be developed.

Alexa: No, don't say that. (higher pitch, fades out)

Grant: Because when they develop and write you a letter saying "Hey should we do it?", you are just like, "I just want to cuddle my dog and watch Netflix."
Alexa: They would not, like, send me a letter 'cause I'm not that important.

Grant: You gotta wait, by the time World War III comes, you've already won your Nobel Prize.

Alexa: Oh, yeah.

Grant: You are a doctor of research at MIT, why not.

Alexa: Oh yeah. You have my whole life figured out now. (laughs)

Grant: Then they write that letter saying, "Hey, smartest person in the world, what should we do?"

Alexa: No.

Grant: You never know.

Alexa: Not me.

In this episode, Alexa cites her preference to sit out of the ethical discussion, but acknowledges that it's "probably worse" to do so. Grant challenges her by comparing her to the scientists she just criticized, which she does not like. She resists this comparison by claiming that she is "not important" so no one would ask her opinion. Grant pushes her to see herself as a future expert scientist who others would look to for advice, and she continues to push back. Alexa's articulated lack of agency here overshadows her engagement in ethical reasoning. It is unclear to what extent this is because she struggles to see herself as in the same role as the decisionmakers during the Manhattan Project, or because she is simply uncomfortable with the idea of having to make a decision (as she mentioned in Episode 1). It is also possible that a combination of these factors is at play: that her response is a combination of discomfort and feeling that her inability to influence others doesn't warrant overcoming that discomfort.

A while later, the group has moved on to their last page of prompts for the day. This prompt asks students to compare two letters from groups of scientists: one letter from a group chaired by Franck, entitled "Advising Against the Bomb," and the other letter from the Science Panel advocating for dropping the bomb (discussed in Episodes 2 and 3). The prompt reads: "In what ways do you agree with the arguments made by the authors of the Franck report and/or the Science Panel? Who do you agree with more? Who do you disagree with?"

\section{Episode 4: I take it with Franck}

Alexa: There's a back, (reads aloud): "Which do you agree with more ..." (answers her own question): Franck, Franck, Franck. I agree with Franck more.

Grant: Or the Science Panel. So we have to argue...

Alexa: It's a personal question, in what ways do you agree with?

Grant: In personal, I don't take an apathetic approach. I don't approve of it, I take it all the time but I don't approve of just saying... (throws his hands up) "I'unno"

Alexa: I'm against, I take it with Franck. (sings) F-RA-N-K 
Grant: I don't think unilaterally. (seemingly to Doug) What do you think is the easiest stance to take?

Doug (LA): I'm not gonna... I don't feel like it's productive for me to say the easiest stance because that's definitely up to each individual person. I know what my stance is, but I'm saying... I would say it's easier to not take a stance than to define, like, "I think this is what we should..."

Grant: I would say so, yeah.

Doug (LA): Indecision is more often than not, it's easier to take than making a decision.

Alexa: I agree with Franck more.

Doug (LA): With who?

Alexa: Franck, I'm probably butchering that name.

Doug (LA): So what was his view?

Alexa: His view was against the use of nuclear weapons.

In contrast to earlier episodes, Alexa is very explicit about her opinion here. Instead of resisting a stance, she answers her own question in the same moment that she reads the prompt and sings her opinion. When Grant and Doug are speaking back and forth, she interjects plainly to repeat her stance once again. And when Doug asks her what Franck's opinion is, she plainly states that he is against the use of nuclear weapons.

Doug continues to elicit information from Alexa about Franck's stance, and she volunteers a reflection.

\section{Episode 5: I wouldn't have rights}

Alexa: I understand why it's easy for me to say I'm against it because I wasn't at the time. And obviously if I was at the time, I wouldn't have... I'm a woman, I wouldn't even have an opinion, I'd be in the States and I'd probably be banned because I'm mixed, so... (makes a swinging arm gesture) ...I wouldn't have rights!

In thinking of herself in the historical context of the development of the atomic bomb, Alexa explicitly refers to her race and gender as displacing her from the conversation if she were around at that time. This understanding may inform some of her earlier hesitance to see herself as being "important" in the context of the the discussion. This last episode is interesting to us because it suggests that Alexa's positionality coupled with the history of racism and sexism in the U.S. may be one of the factors limiting her participation.

\section{DISCUSSION AND CONCLUSIONS}

Overall, we see Alexa initially resisting engaging in sensemaking around ethical issues but ultimately becoming more engaged and articulating a clearer stance. Each of the instances of her resisting or offering her opinions give us insight into what factors may be limiting or enabling her engagement. The curricular materials themselves offer support for Alexa by eliciting students' reactions to the stances taken by specific scientists. This invites Alexa to develop her opinions. Alexa's peers also push her to engage in this reasoning process, even when she initially says it makes her uncomfortable to do so. Similarly, the LA (Doug) empathizes with Alexa's sentiment that the conversation is difficult and further pushes her to acknowledge and voice her gut instincts. The lead instructor also encourages Alexa by validating her interpretation that specific physicists abdicated their responsibilities when advising about the use of the first atomic bomb.

Despite these instructional supports and her ultimate successes, Alexa did struggle along the way. We see the reasons for her struggle as unsurprising given her positionality and her lack of past opportunities to engage in ethical discussions in the classroom. She expresses discomfort around engaging in conversations with little practice to inform her, which we see as tied to her past experiences in the classroom. We also note that Alexa resists being positioned as an expert scientist by her peer (Grant). She implies that political leaders would not care what she thinks and uses that as a reason to "check out." Later on, Alexa reflects on how her race and gender would have caused others to exclude her from critical conversations about science ethics. Thus, we see that Alexa's minoritized status within our exclusive and discriminatory society could be limiting her engagement in this conversation.

These results suggest that ethical conversations in the classroom can be productive, but additional attention to minoritized students' experiences within these conversations is warranted. Instructors who implement similar curricula should be attentive to students' struggles to see themselves as agentive within the scientific community, and could explicitly acknowledge how factors like race and gender may be contributing to these struggles. We also notice that many of the challenges that arose in these episodes could have been addressed at other points throughout the curriculum. For example, we noticed that the prominent voices in this historical example reinforced a history of exclusion in our society. Telling counterstories of minoritized people overcoming barriers to participation could be an effective buffer against these historical inequities [33]. Explicit discussions about underrepresentation in STEM could also help Alexa to understand the sources of some of her struggles and feel validated in pointing out past injustices [34-38]. Finally, fostering a sense of belonging in students through meaningful physics recognition [39-41] could help Alexa and students like her see themselves as scientists who can take a seat at the table. All of these together could contribute to students experiencing a greater sense of agency within the physics community, which could in turn motivate them to engage in difficult discussions about science ethics and take action to right and prevent potential injustices.

\section{Acknowledgments}

The authors thank the TXST PER group, especially Alexander Vasquez, as well as Fidel Amezcua, Gina Quan, and Chandra Turpen for contributions to ideas in this paper. 


\section{References}

[1] Mark S. Frankel. "An empirical exploration of scientists' social responsibilities". In: Journal of Responsible Innovation 2.3 (2015), pp. 301-310.

[2] Jessica M. Wyndham, Robert Albro, Joshua Ettinger, Kathryn Smith, Maya Sabatello, and Mark S. Frankel. "Social responsibility: A preliminary inquiry into the perspectives of scientists, engineers and health professionals". In: Washington, DC: American Association for the Advancement of Science. Accessed July 19 (2015), p. 2015.

[3] Cecilie Glerup and Maja Horst. "Mapping 'social responsibility'in science". In: Journal of Responsible Innovation 1.1 (2014), pp. 31-50.

[4] Heather E. Douglas. "The moral responsibilities of scientists (tensions between autonomy and responsibility)". In: American Philosophical Quarterly 40.1 (2003), pp. 59-68.

[5] Bertrand Russell. "The social responsibilities of scientists". In: Science (1960).

[6] Stephanie J. Bird. "Social responsibility and research ethics: not either/or but both". In: Professional Ethics Report 27.2 (2014).

[7] Stephanie J. Bird. "Socially responsible science is more than "good science"”. In: Journal of microbiology \& biology education 15.2 (2014), p. 169.

[8] Jack Stilgoe, Richard Owen, and Phil Macnaghten. "Developing a framework for responsible innovation". In: Research policy 42.9 (2013), pp. 1568-1580.

[9] Michael Gibbons. "Science's new social contract with society”. In: Nature 402.6761 (1999), pp. C81-C84.

[10] J. M. Ladd, M. D. Lappé, J. B. McCormick, Boyce, and M. K. Cho. "The "how" and "whys" of research: life scientists' views of accountability". In: Journal of medical ethics 35.12 (2009), pp. 762-767.

[11] David B. Resnik and Kevin C. Elliott. "The ethical challenges of socially responsible science". In: Accountability in research 23.1 (2016), pp. 31-46.

[12] Erin A. Cech. "Culture of disengagement in engineering education?" In: Science, Technology, \& Human Values 39.1 (2014), pp. 42-72.

[13] L. Wolpert. "The social responsibility of scientists: moonshine and morals". In: BMJ (Clinical research ed.) 298.6678 (1989), pp. 941-943. DOI: 10.1136/bmj.298.6678.941.

[14] Erin A. Cech. "The (mis) framing of social justice: Why ideologies of depoliticization and meritocracy hinder engineers' ability to think about social injustices". In: Engineering education for social justice. Springer, 2013, pp. 67-84.

[15] Sandra Harding. Objectivity and diversity: Another logic of scientific research. University of Chicago Press, 2015.

[16] Ebony McGee and Lydia Bentley. "The equity ethic: Black and Latinx college students reengineering their STEM careers toward justice". In: American Journal of Education 124.1 (2017), pp. 1-36.
[17] Juan C. Garibay. 'STEM students' social agency and views on working for social change: Are STEM disciplines developing socially and civically responsible students?" In: Journal of Research in Science Teaching 52.5 (2015), pp. 610-632. DOI: 10.1002/tea.21203.

[18] Infusing Ethics Selection Committee et al. Infusing ethics into the development of engineers: Exemplary education activities and programs. National Academies Press, 2016.

[19] David R. Haws. "Ethics Instruction in Engineering Education: A (Mini) Meta-Analysis". In: Journal of Engineering Education 90.2 (2001), pp. 223-229. DOI: 10.1002/j.2168-9830. 2001.tb00596.x.

[20] Jessica Li and Shengli Fu. "A systematic approach to engineering ethics education". In: Science and engineering ethics 18.2 (2012), pp. 339-349.

[21] David R. Haws. "The importance of meta-ethics in engineering education". In: Science and engineering ethics 10.2 (2004), pp. 204-210. DOI: 10.1007/s11948-004-0015-7.

[22] Justin L. Hess, Johannes Strobel, and Andrew O. Brightman. "The Development of Empathic Perspective-Taking in an Engineering Ethics Course". In: Journal of Engineering Education 106.4 (2017), pp. 534-563. DOI: 10.1002/jee.20175.

[23] Egla Ochoa-Madrid, Alice R. Olmstead, and Brianne Gutmann. "Examining Students Views on Ethics and the Atomic Bomb". In: Physics Education Research Conference 2019. PER Conference. Provo, UT, 2019.

[24] Benjamin W. Dreyfus, Erin Ronayne Sohr, Ayush Gupta, and Andrew Elby. “"Classical-ish”: Negotiating the Boundary between Classical and Quantum Particles". In: Physics Education Research Conference 2015. PER Conference. College Park, MD, 2015, pp. 111-114.

[25] Eleanor W. Close, Jessica Conn, and Hunter G. Close. "Becoming physics people: Development of integrated physics identity through the Learning Assistant experience". In: Phys. Rev. Phys. Educ. Res. 12.1 (2016), p. 010109. DOI: 10.1103/ PhysRevPhysEducRes.12.010109.

[26] Brian Arao and Kristi Clemens. "From safe spaces to brave spaces". In: The art of effective facilitation: Reflections from social justice educators (2013), pp. 135-150.

[27] Tom L. Beauchamp. "The 'four principles' approach to health care ethics". In: Principles of health care ethics 29 (2007), pp. 3-10.

[28] Cynthia C. Kelly. Manhattan Project: The Birth of the Atomic Bomb in the Words of Its Creators, Eyewitnesses, and Historians. Black Dog \& Leventhal, 2009.

[29] Barbara Rogoff. Apprenticeship in thinking: Cognitive development in social context. Oxford university press, 1990.

[30] Lev Semenovich Vygotsky. Mind in society: The development of higher psychological processes. Harvard university press, 1980.

[31] Randi A Engle, Faith R Conant, and James G Greeno. "Progressive refinement of hypotheses in video-supported research". In: Video research in the learning sciences (2007), pp. 239-254.

[32] Robert K Yin. Case study research and applications: Design and methods. Sage publications, 2017. 
[33] Katemari Rosa and Felicia Moore Mensah. "Educational pathways of Black women physicists: Stories of experiencing and overcoming obstacles in life". In: Physical Review Physics Education Research 12.2 (2016), p. 020113.

[34] Moses Rifkin. "Addressing underrepresentation: Physics teaching for all”. In: The Physics Teacher 54.2 (2016), pp. 7274.

[35] Abigail R. Daane and Vashti Sawtelle. "Student discourse about equity in an introductory college physics course". In: 2016 PERC (2016), pp. 88-91.

[36] Abigail R. Daane, Sierra R. Decker, and Vashti Sawtelle. "Teaching about racial equity in introductory physics courses". In: The Physics Teacher 55.6 (2017), pp. 328-333.

[37] Robynne M Lock and Zahra Hazari. "Discussing underrepresentation as a means to facilitating female students' physics identity development”. In: Physical Review Physics Education Research 12.2 (2016), p. 020101.

[38] American Physical Society. Step Up. https://engage.aps.org/stepup/home. Online; accessed 2020.

[39] Zahra Hazari and Cheryl Cass. "Towards meaningful physics recognition: What does this recognition actually look like?" In: The Physics Teacher 56.7 (2018), pp. 442-446.

[40] Zahra Hazari, Gerhard Sonnert, Philip M. Sadler, and MarieClaire Shanahan. "Connecting high school physics experiences, outcome expectations, physics identity, and physics career choice: A gender study". In: Journal of Research in Science Teaching 47.8 (2010), pp. 978-1003.

[41] Simone Hyater-Adams, Claudia Fracchiolla, Noah D. Finkelstein, and K. A. Hinko. "Understanding connections between physics and racial identities through recognition and relational resources”. In: 2016 PERC Proceedings (2016), pp. 164-167. 